J. Amer. Soc. Hort. ScI. 117(6):941-945. 1992.

\title{
Supercooling and Extracellular Ice Formation in Differentiating -Buds of Eastern Thornless Blackberry
}

\author{
Michele R. Warmund \\ Department of Horticulture, University of Missouri, Columbia, MO 65211
}

Fumiomi Takeda and Glen A. Davis

Appalachian Fruit Research Station, U.S. Department of Agriculture, Agricultural Research

Service, Kearneysville, WV 25430

Additional index words. Rubus spp., cold hardiness, differential thermal analysis, flowering

\begin{abstract}
Hull Thornless' and 'Black Satin' blackberry (Rubus spp.) canes were collected from Sept. 1989 through Mar. 1990 to determine the hardiness and supercooling characteristics of buds at various stages of development. Anatomical studies were also conducted to examine the location of ice voids in buds frozen to $\mathbf{- 5}$ or $\mathbf{- 3 0 C}$. Differentiation of the terminal flower occurred in 'Black Satin' buds by 6 Nov., whereas 'Hull Thornless' buds remained vegetative until early spring. As many as nine floral primordia were observed in both cultivars by 12 Mar. The hardiness of the two cultivars was similar until February. Thereafter, 'Black Satin' buds were more susceptible to cold injury than those of 'Hull Thornless'. Flora1 and undifferentiated buds of both cultivars exhibited one to four low temperature exotherms (LTEs) from 9 Oct. to 12 Mar. in differential thermal analysis (DTA) experiments. The stage of flora1 development did not influence the bud's capacity to supercool. The number of LTEs was not related to the stage of floral development or to the number of floral primordia. Extracellular voids resulting from ice formation in the bud axis and scales were observed in samples subjected to -5 or $\mathbf{- 3 0 C}$.
\end{abstract}

Low temperature injury is a major factor limiting commercial production of eastern thornless blackberry. Midwinter temperatures below -20C frequently injure floral buds and reduce yield. Kraut et al. (1986) reported that 'Smoothstem' was the most susceptible to cold injury, 'Hull Thornless' was intermediate, and 'Dirksen' was the least susceptible when the relative bud hardiness of three thornless blackberries was evaluated. In another study (Warmund and George, 1990), 'Chester' and 'Hull Thornless' buds had similar $\mathrm{T}_{50}$ (temperature at which $50 \%$ of the buds are dead) values $(-15 \mathrm{C})$ in November, while those of 'Dirksen' were one degree hardier.

In blackberry, the time of floral bud differentiation and bloom are variable (Moore and Caldwell, 1985; Robertson, 1957; Waldo, 1933). Takeda and Wisniewski (1989) reported that 'Black Satin' and 'Hull Thornless' blackberry differentiate floral buds in October and late March, respectively. In both cultivars, anthesis of the terminal flower of the $A_{1}$ axis preceded that of the terminal flower on each of the $\mathrm{A}_{2}$ axes. Anthesis then progressed acropetally from the basal floral primordia of the $A_{1}$ axis.

Most thorny, erect-type blackberries develop floral buds in early fall (Warmund and George, 1990). In 'Darrow' blackberry, the supercooling characteristics of the buds changed as floral differentiation progressed (Warmund et al., 1988). A single LTE was associated with injury to the entire floral region in September, when buds were at an early stage of floral development. As many as ten LTEs were observed at later stages of floral differentiation, indicating that individual primordia froze and were injured independently. In contrast, differentiating floral primordia of other blackberry cultivars, such as 'Shawnee' and 'Dirksen', did not freeze independently in midwinter (Warmund and George, 1989, 1990). More recent studies indicated

Received for publication 23 Dec. 1991. Accepted for publication 19 May 1992. Contribution from the Missouri Agr. Expt. Sta., J. Ser. no. 11577. We gratefully acknowledge the technical assistance of Milon George. The cost of publishing this paper was defrayed in part by the payment of page charges. Under postal regulations, this paper therefore must be hereby marked advertisement solely to indicate this fact. that the supercooling characteristics of differentiating Rubus floral primordia may be related to the formation of extracellular ice within buds (Schaffer et al., 1991b).

The purpose of this study was: 1) to compare the susceptibility of 'Black Satin' and 'Hull Thornless' blackberry buds to low temperature injury at various stages of floral development, 2) to determine if there is a relationship between floral morphology and the supercooling characteristics of buds, and 3) to examine the location of ice formation in bud tissues.

\section{Materials and Methods}

Sampling. 'Hull Thornless' and 'Black Satin' canes were collected from 6-year-old plants at the Appalachian Fruit Research Station, Kearneysville, W.Va. Samples were obtained at $1.2 \pm$ $0.2 \mathrm{~m}$ above the soil surface on 11 Sept., 9 Oct., 6 Nov., and 11 Dec. 1989 and 8 Jan., 5 Feb., 25 Feb., and 12 Mar. 1990 for DTA, viability tests, and floral stage ratings. 'Hull Thornless' samples were also collected on 29 Mar. At the last collection, one group of samples was selected that had tightly closed buds. The second group of samples had $2 \mathrm{~cm}$ of growth from the buds. From 6 Nov. 1989 through 29 Mar. 1990, 10 to 31 buds of both cultivars were placed in formalin-acetic acid-alcohol (FAA) fixative (Sass, 1958) at each sampling date, and the developmental stage of each sample was recorded according to the rating system (Table 1) described by Takeda and Wisniewski (1989).

Canes collected for viability tests and DTA were sealed in plastic bags containing moist paper towers, packed on ice, and shipped by overnight mail to the Univ. of Missouri. Samples were stored at $2 \mathrm{C}$ until freezing tests were performed.

Viability tests. All viability tests were conducted within $48 \mathrm{~h}$ of receiving the plant material. Five, two-node cane sections were placed in moist cheesecloth and wrapped in aluminum foil

Abbreviations: DTA, differential thermal analysis; FAA, formalin-acetic acidalcohol; LTEs, low temperature exotherms. 
Table 1. Numerical rating system for stages of bud development in 'Black Satin' and 'Hull Thornless' eastern thornless blackberries.

\begin{tabular}{cc}
\hline \hline Stage & Description \\
\hline 1 & Bud is vegetative with only leaf primordia encircling the \\
apical meristem. \\
2 & Development of inflorescence axis is evident. \\
3 & The apex of inflorescence axis is enlarged. \\
4 & Sepals differentiated on terminal flower. \\
5 & Petal primordia are differentiated. The central receptacle of \\
the terminal flower begins to enlarge. \\
6 & Receptacle of terminal flower is elongated and petal pri- \\
7 & mordia are prominent. \\
8 & Gynen primordia are differentiated on floral cup. \\
9 & Gynaped receptacle. \\
petals are enlarged. & The anther and filament of stamens and the ovary, style, \\
and stigma of pistils are visible.
\end{tabular}

for each of the six test temperatures. Tissue temperature was monitored with 0.51-mm-diameter (24-gauge) copper-constan$\tan$ thermocouples attached to the samples. Thermocouple output was recorded on a Honeywell Electronik 112 multipoint recorder (Honeywell, Fort Washington, Pa.). Samples were placed in a programmable freezer (Tenney Engineering, Union, N.J.) and kept at $-3 \mathrm{C}$ for $12 \mathrm{~h}$. During this time, the cheesecloth froze and seeded the tissue with ice at about -1C. After the $12 \mathrm{~h}$, samples were cooled at $3 \mathrm{C} / \mathrm{h}$ and removed from the freezer at $3 \mathrm{C}$ intervals at temperatures estimated to result in bud injury. The tissue was then thawed in a refrigerator at $2 \mathrm{C}$ for $24 \mathrm{~h}$. Unfrozen controls, maintained at $2 \mathrm{C}$ during the freezing test, and samples that were subjected to freezing were then incubated at $23 \pm 2 \mathrm{C}$ at $100 \%$ relative humidity $(\mathrm{RH})$ for 7 days. Afterward, buds were sectioned with a razor blade and examined for oxidative browning under a dissecting microscope at $\times 40$. The number of injured and uninjured floral primordia were recorded, and a modified Spearman-Karber equation (Bittenbender and Howell, 1974) was used to calculate $T_{50}$ values for buds at each sampling date. The temperature at which all visible primordia were injured was used as the highest lethal temperature in the equation. Data were subjected to an analysis of variance and means were compared by a t test.

DTA. Intact primary buds were removed from canes with a small section of adjacent stem tissue. Each sample was wrapped in moistened cheesecloth (to seed the tissue with ice), placed in an aluminum foil cup, and attached to a thermistor in the DTA system described by George (1982). An empty aluminum foil cup was also placed in contact with the reference sensor to balance the heat capacity of the reference and sample chambers. The temperature was lowered rapidly to $0 \mathrm{C}$ and cooling at $3 \mathrm{C} /$ $\mathrm{h}$ was initiated when the bud temperature was within $1 \mathrm{C}$ of the reference temperature. Data were collected at 40 -sec intervals until the sample temperature reached $-40 \mathrm{C}$.

After DTA was completed, buds were removed from the freezing chamber and fixed in FAA. Samples were then mailed to the Appalachian Fruit Research Station, where the developmental stage of each bud was recorded. Regression analysis was performed to determine the relationship between the number of LTEs per bud and the stage of floral bud development.

Freeze-fixation. From January to March, 'Black Satin' and 'Hull Thornless' samples were collected for freeze-fixation to examine the location of extracellular ice in frozen buds. The basal end of a cane with one bud was dipped in a colony of an ice nucleation active strain of Pseudomonas syringae (van Hall) to initiate ice formation, and individual samples were placed in test tubes with the basal end of the cane in $1 \mathrm{ml}$ of deionized water. Test tubes were submerged in a circulating ethylene glyco1 bath (Neslab Instruments, Portsmouth, N.H.) at 0C for 30 min and cooled at $5 \mathrm{C} / \mathrm{h}$ to a tissue temperature of $-30 \mathrm{C}$. Tissue temperature was monitored with 0.25 -mm-diameter (30-gauge) copper-constantan thermocouples attached to individual buds. A datalogger interfaced to a computer (Dianachart, Rockaway, N.J.) recorded temperatures at 30-sec intervals. Samples were then warmed to $-5 \mathrm{C}$, immersed in a precooled $(-5 \mathrm{C})$ solution of $8 \%$ formaldehyde $(\mathrm{v} / \mathrm{v})$, and fixed while frozen as described by MacKenzie et al. (1975). Specimens remained in the fixative for 7 days at $-5 \mathrm{C}$. The formaldehyde solution was then replaced with $50 \%$ ethanol precooled to $-5 \mathrm{C}$, and kept at this temperature for $30 \mathrm{~min}$. After warming the samples to $23 \mathrm{C}$, the tissue was dehydrated in a graded ethanol series. Buds were then bisected longitudinally with a razor blade in absolute ethanol and immersed in two additional exchanges of absolute ethanol. Samples were critical-point dried with $\mathrm{CO}_{2}$, sputter coated with gold-palladium, and examined on a SteroScan 120 microscope (Cambridge Instruments, Cambridge, England) operated at 10 $\mathrm{kV}$. Additional samples were subjected to freeze-fixation at $-5 \mathrm{C}$, and nonfrozen controls were fixed in FAA and prepared for scanning electron microscopy as described above.

\section{Results and Discussion}

Enlargement of the inflorescence apex (stage 3) was observed in 'Black Satin' buds collected on 6 Nov. (Fig. 1). Buds remained at this stage of bud development through January. Sepal initiation and enlargement (stage 4) was observed on the terminal flower of the $A_{1}$ axis of some buds on 6 Feb. The receptacle of the terminal flower in most 'Black Satin' buds had elongated, with sepals and petals visible in an alternate arrangement (stage 6) on 12 Mar. In contrast, most 'Hull Thornless' buds remained vegetative (stage 1) through 6 Feb. Development of the inflorescence axis (stage 2) was apparent on 25 Feb. By 26 Mar., sepals on the terminal flower had begun differentiation (stage 4) in most samples. Takeda and Wisniewski (1989) ob-

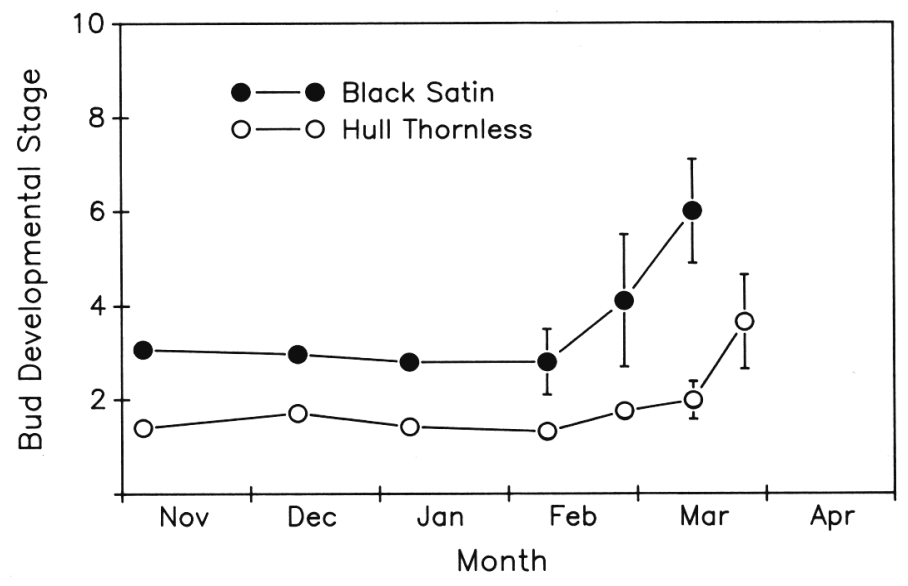

Fig. 1. Development of primary axillary buds of two cultivars of eastern thornless blackberry from 1989 to 1990. The rating system was from 1 (bud was vegetative) to 10 (all reproductive organs differentiated). Refer to Table 1 for the specific description of each developmental stage. Missing SE bars were smaller than graph symbols. 
served inflorescence development of the $\mathrm{A}_{1}$ apex of 'Black Satin' buds in October, but most buds remained vegetative with little or no differentiation until January. When growth resumed, inflorescence development of 'Hull Thornless' lagged $\approx 2$ weeks behind that of 'Black Satin'. Differentiation of the terminal flower was not apparent in 'Hull Thornless' buds until March.

Viability tests. Blackberry cultivars had similar $\mathrm{T}_{50}$ values at each collection date from September through January (Table 2). Thereafter, 'Black Satin' buds had higher $\mathrm{T}_{50}$ values than those of 'Hull Thornless'. Both cultivars had the lowest $\mathrm{T}_{50}$ value in December and deacclimated rapidly after $25 \mathrm{Feb}$. In the 12 Mar. test, nearly all 'Black Satin' buds started to grow during the incubation period following the freezing treatment. In contrast, very few of the 'Hull Thornless' buds grew during incubation. When 'Hull Thornless' buds were tested on 29 Mar., those at a tight bud stage when exposed to freezing temperatures survived $-9 \mathrm{C}$, while samples with $2 \mathrm{~cm}$ of growth only survived $-6 \mathrm{C}$.

In September and October, buds of both cultivars were at stage 1 with no apparent differentiation of terminal or lateral floral primordia (Table 2). By 6 Nov., one to five floral primordia per bud were observed in 'Black Satin' samples. Nine floral primordia were evident in $73 \%$ of the buds by 8 Jan. By 25 Feb., all samples examined had nine floral primordia per bud. In contrast, multiple floral primordia were not observed in 'Hull Thornless' buds until 12 Mar. Seven buds from the March collection had nine floral primordia each, but the terminal flower on the inflorescence axis was not developed in more than half the buds. In earlier work, Takeda (1987) observed as many as 40 flowers per inflorescence during bloom in 'Black Satin' and 'Hull Thornless'. Although there might have been more floral primordia present in blackberry buds in this study, only nine were distinguishable with a dissecting microscope at $\mathrm{x} 40$.

DTA. No LTEs were detected by DTA at the September collection date (Tables 3 and 4). In October, all but one 'Black Satin' bud exhibited a LTE. One or two LTEs were present in half of the 'Hull Thornless' buds subjected to DTA. From 6 Nov. to 12 Mar. one or two LTEs per bud were generally detected in each cultivar (Fig. 2). However, one sample of each cultivar collected on 6 Nov. exhibited four LTEs. The reason for the increased number of LTEs during November is unclear. By 29 Mar., 'Hull Thornless' samples that had $2 \mathrm{~cm}$ of growth from the buds did not exhibit LTEs.

The temperature range of LTEs measured within individual

Table 2. $\mathrm{T}_{50}$ values and number of differentiated floral primordia per bud of 'Black Satin' and 'Hull Thornless' blackberry buds collected from 11 Sept. 1989 to 12 Mar. 1990.

\begin{tabular}{|c|c|c|c|c|}
\hline \multirow[b]{2}{*}{ Collection date } & \multicolumn{4}{|c|}{$\mathrm{T}$} \\
\hline & 'Black & Satin' & 'Hull Thornless' & Significance \\
\hline 11 Sept. 1989 & -6.9 & $(0)^{y}$ & $-6.6(0)$ & NS \\
\hline 9 Oct. 1989 & -10.5 & $(0)$ & $-9.3(0)$ & NS \\
\hline 6 Nov. 1989 & -18.6 & $(1-5)$ & $-17.1(0)$ & NS \\
\hline 11 Dec. 1989 & -20.7 & $(1-5)$ & $-22.2(0)$ & NS \\
\hline 8 Jan. 1990 & -18.9 & (1-9) & $-20.1(0)$ & NS \\
\hline 5 Feb. 1990 & -19.8 & (1-9) & $-21.6(0)$ & \\
\hline 2.5 Feb. 1990 & -17.4 & (9) & $-20.1(0)$ & $*$ \\
\hline 12 Mar. 1990 & -11.4 & (9) & $-16.2 \quad(0-9)$ & $*$ \\
\hline
\end{tabular}

${ }^{2}$ Means were compared by a $t$ test.

${ }^{\prime}$ Numbers in parentheses indicate the number of differentiated floral primordia observed at less than or equal to $\times 40$ under a dissecting microscope.

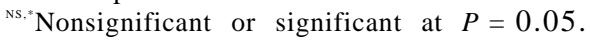

buds was as great as $16 \mathrm{C}$. There was also considerable variability in the LTEs of buds within each collection date. This type of variability in DTA results has been previously reported in similar studies with 'Dirksen' and 'Shawnee' blackberry (Warmund and George, 1989, 1990). Because of the varying LTE number and range of temperatures, it was difficult to compare DTA results with those obtained from viability tests. The ability to conduct DTA on numerous buds (i.e., a larger sample size) and viability tests simultaneously would facilitate the comparison of these experimental results. In spite of these difficulties, the relationship between injury observed in viability tests and LTEs measured by DTA has been confirmed in blackberry (Warmund et al., 1988) and numerous fruit species (Andrews et al., 1984; Andrews and Proebsting, 1987; Biermann et al., 1979; Quamme, 1974).

In Prunus avium L. thawing buds at $2 \mathrm{C}$ for $8 \mathrm{~h}$ increased the LTE,,, (median low temperature exotherm) by $\approx 8 \mathrm{C}$ (Andrews and Proebsting, 1987). After $24 \mathrm{~h}$ of thawing, the LTE, stabilized at $-20 \mathrm{C}$, which was the minimum hardiness level. In our study, blackberry buds did not appear to deacclimate with storage at 2C. For example, LTEs detected from 'Black Satin' buds on 9 Jan. were at a higher temperature than those detected from buds tested on 14 Jan.

When the number of LTEs per bud was regressed with the stage of bud development, the goodness of fit values for 'Black Satin' and 'Hull Thornless' samples were 0.053 and 0.007, respectively. Thus, the number of the LTEs was poorly correlated to the stage of bud development. Additionally, the number of floral primordia on the inflorescence axis did not correspond to the number of LTEs per bud. These results indicate that several floral primordia froze simultaneously in buds that had multiple primordia since one to four LTEs were detected per sample.

Freeze-fixation. All bud tissues and the adjacent bud axis were intact in the nonfrozen control samples fixed in FAA (Fig. $3 \mathrm{~A})$. Extracellular voids were present in the scales surrounding the inflorescence and in the bud axis of samples that were frozen to -5 or $-30 \mathrm{C}$ and freeze-fixed (Fig. 3B). However, voids or tissue aberrations were absent in the inflorescence axis and in developing floral primordia of 'Black Satin' and 'Hull Thornless' buds, indicating that large extracellular ice crystals did not form in these tissues. The absence of voids in portions of the inflorescence above the bud axis following exposure to $-30 \mathrm{C}$ was surprising and in contrast to the observations previously reported for Prunus persica (L.) Batsch (Ashworth et al., 1989).

Floral primordia in buds of several Rubus spp. survive freezing by retaining a fraction of water in a supercooled state (Kraut et al., 1986; Warmund and George, 1990). However, the supercooling characteristics differ among cultivars and species. Floral primordia in buds of the erect, thorny 'Darrow' blackberry were injured by intracellular ice formation associated with a single LTE when few differentiated primordia were present in early fall (Warmund et al., 1988). In midwinter, when nine floral primordia were evident, most primordia nucleated and froze independently. In other Rubus spp., such as 'Reveille' and 'Nordic' red raspberry and 'Shawnee' and 'Dirksen' blackberry, LTEs detected in DTA were associated with freezing injury, but their number did not correspond to the number of differentiated floral primordia (Warmund and George, 1989, 1990). Results from our study demonstrate that 'Black Satin' and 'Hull Thornless' buds have similar supercooling characteristics to the latter group of Rubus spp.

In $P$. persica, supercooling of the floral primordium was re- 
Table 3. LTEs of 'Black Satin' blackberry buds subjected to DTA.

\begin{tabular}{|c|c|c|c|c|c|}
\hline \multirow[b]{2}{*}{ Collection date } & \multirow{2}{*}{$\begin{array}{c}\text { DTA } \\
\text { test date }\end{array}$} & \multicolumn{4}{|c|}{ LTE temperature $\left({ }^{\circ} \mathrm{C}\right)$} \\
\hline & & & ud 1 & Bud 2 & Bud 3 \\
\hline 11 Sept. 1989 & 12 Sept. & No LTE & & No LTE & No LTE \\
\hline 11 Sept. 1989 & 18 Sept. & No LTE & & No LTE & No LTE \\
\hline 9 Oct. 1989 & 10 Oct. & -15.6 & & No LTE & -14.5 \\
\hline 9 Oct. 1989 & 12 Oct. & -9.7 & & -13.0 & -14.2 \\
\hline 6 Nov. 1989 & 7 Nov. & $-20.1,21.5$ & & -18.3 & -17.0 \\
\hline 6 Nov. 1989 & 9 Nov. & $-10.2,-12.2$ & $,-14.1,-16.2$ & -17.2 & -14.9 \\
\hline 11 Dec. 1989 & 12 Dec. & $-17.1 \quad(4)^{2}$ & & $-20.2(2)$ & $-15.6 \quad(3)$ \\
\hline 11 Dec. 1989 & 14 Dec. & $-16.2(3)$ & & $-17.6(3)$ & No LTE \\
\hline 8 Jan. 1990 & 9 Jan. & -11.0 & (3) & $-18.6 \quad(2)$ & -16.4 \\
\hline 8 Jan. 1990 & 10 Jan. & -19.8 & & -22.0 & -16.3 \\
\hline 8 Jan. 1989 & 14 Jan. & $-22.7(2)$ & & No LTE (4) & -19.4 \\
\hline 5 Feb. 1990 & 6 Feb. & $-11.4 \quad(3)$ & & $-12.4 \quad(4)$ & No LTE \\
\hline 5 Feb. 1990 & 9 Feb. & $-16.4, \quad-20.1$ & (3) & $-11.7(5)$ & $-13.2 \quad(3)$ \\
\hline 25 Feb. 1990 & 4 Mar. & $-14.5 \quad(3)$ & & $-15.8 \quad(5)$ & $-19.4 \quad(2)$ \\
\hline 25 Feb. 1990 & 5 Mar. & $-16.8 \quad(2)$ & & $-21.1(3)$ & $-12.1,-20.4(3)$ \\
\hline 12 Mar. 1990 & 13 Mar. & No LTE (5) & & $-23.4(5)$ & $-15.4 \quad(2)$ \\
\hline 12 Mar. 1990 & 14 Mar. & $-18.8 \quad(2)$ & & NOLTE & -11.8 \\
\hline
\end{tabular}

${ }^{2}$ Number in parentheses represents the stage of bud development. Developmental stages were not evaluated on these buds before 11 Dec. 1989, or on samples tested on 10 Jan. 1990.

Table 4. LTEs of 'Hull Thornless' blackberry buds subjected to DTA.

\begin{tabular}{|c|c|c|c|c|c|}
\hline \multirow[b]{2}{*}{ Collection date } & \multirow{2}{*}{$\begin{array}{c}\text { DTA } \\
\text { test date }\end{array}$} & \multicolumn{4}{|c|}{ LTE temperature $\left({ }^{\circ} \mathrm{C}\right)$} \\
\hline & & $\mathrm{Bu}$ & 1 & Bud 2 & Bud 3 \\
\hline 11 Sept. 1989 & 14 Sept. & No LTE & & No LTE & No LTE \\
\hline 11 Sept. 1989 & 19 Sept. & No LTE & & No LTE & No LTE \\
\hline 9 Oct. 1989 & 11 Oct. & -17.0 & & -14.6 & No LTE \\
\hline 9 Oct. 1989 & 13 Oct. & No LTE & & -13.6 & No LTE \\
\hline 6 Nov. 1989 & 8 Nov. & -14.4 & & No LTE & -19.2 \\
\hline 6 Nov. 1989 & 10 Nov. & $-8.0,-8.3$ & $-9.2,-13.6$ & No LTE & -10.1 \\
\hline 11 Dec. 1989 & 13 Dec. & No LTE $(2)^{2}$ & & $-18.2 \quad(2)$ & $-20.2(2)$ \\
\hline 11 Dec. 1989 & 15 Dec. & $-18.0(2)$ & & $-22.7(1)$ & No LTE (1) \\
\hline 8 Jan. 1990 & 11 Jan. & $-20.8(2)$ & & $-23.4(2)$ & $-19.8 \quad(1)$ \\
\hline $\begin{array}{lll}8 & \text { Jan. } & 1990 \\
5 & \text { Feb. } & 1990\end{array}$ & $\begin{aligned} 12 & \text { Jan. } \\
7 & \text { Feb. }\end{aligned}$ & $\begin{array}{ll}-18.6 & (1) \\
-9.5, & -21.2\end{array}$ & (2) & $\begin{array}{ll}-20.7 & (2) \\
-22.4 & (2)\end{array}$ & $\begin{array}{l}-20.0(2) \\
-22.0(2)\end{array}$ \\
\hline 5 Feb. 1990 & 12 Feb. & $-21.4(2)$ & & $-13.6,-18.8(2)$ & $-20.5(2)$ \\
\hline 25 Feb. 1990 & 3 Mar. & $-23.0(2)$ & & $-15.0(2)$ & $-10.6, \quad-17.6(2)$ \\
\hline 25 Feb. 1990 & 6 Mar. & $-17.4, \quad-21.0$ & (2) & $-20.0(2)$ & $-13.6(2)$ \\
\hline 12 Mar. 1990 & 15 Mar. & $-12.0 \quad(1)$ & & No LTE (2) & No LTE (4) \\
\hline 12 Mar. 1990 & 18 Mar. & No LTE (2) & & $-21.6(1)$ & $-16.0 \quad(2)$ \\
\hline 29 Mar. $1990^{y}$ & 2 Apr. & No LTE (4) & & No LTE (3) & No LTE (4) \\
\hline 29 Mar. $1990^{y}$ & 3 Apr. & No LTE (5) & & No LTE (5) & No LTE (4) \\
\hline
\end{tabular}

${ }^{2}$ Number in parentheses represents the stage of bud development. Developmental stages were not evaluated on these buds before 11 Dec. 1989.

'Samples had 2 to $4 \mathrm{~cm}$ of growth from the buds.

lated to vascular development in the bud axis (Ashworth, 1982, 1984). When vascular tissues were procambial, the floral primordium supercooled. However, this capacity to avoid freezing was lost when vascular continuity was established between the floral primordia and bud axis. In 'Dirksen' blackberry, supercooling also occurred before development of vascular continuity (Schaffer et al., 1991a).

Tissue voids resulting from extracellular ice formation have been reported in Rubus (Schaffer et al., 1991b), Prunus (Ashworth et al., 1989), and Forsythia (Ashworth, 1990). Schaffer et al. (1991b) proposed that extracellular ice lens formation influenced the supercooling characteristics of differentiating 'Darrow' buds. Voids were present in bracts and floral primordia in 'Darrow' buds collected from the field in January. The formation of these lenses corresponded with the capacity of individual primordia to supercool and freeze independently. Thus, ice lenses may isolate differentiated flowers within the bud. In contrast, voids from extracellular ice were present only in the bud axis and scales in 'Shawnee' and 'Dirksen' buds collected at the same time (Schaffer et al., 1991b). The absence of extracellular ice in the developed floral primordia and the subtending bracts may limit the capacity of primordia of these cultivars to freeze independently and produce several LTEs in DTA. Results from DTA and freeze-fixation experiments in this study indicate that extracellular ice formation in 'Black Satin' and 'Hull Thornless' is similar to that in 'Shawnee' and 'Dirksen' buds.

In conclusion, 'Black Satin' buds developed floral primordia and differentiated floral structures much earlier than those of 'Hull Thornless'. However, the capacity of these blackberry 


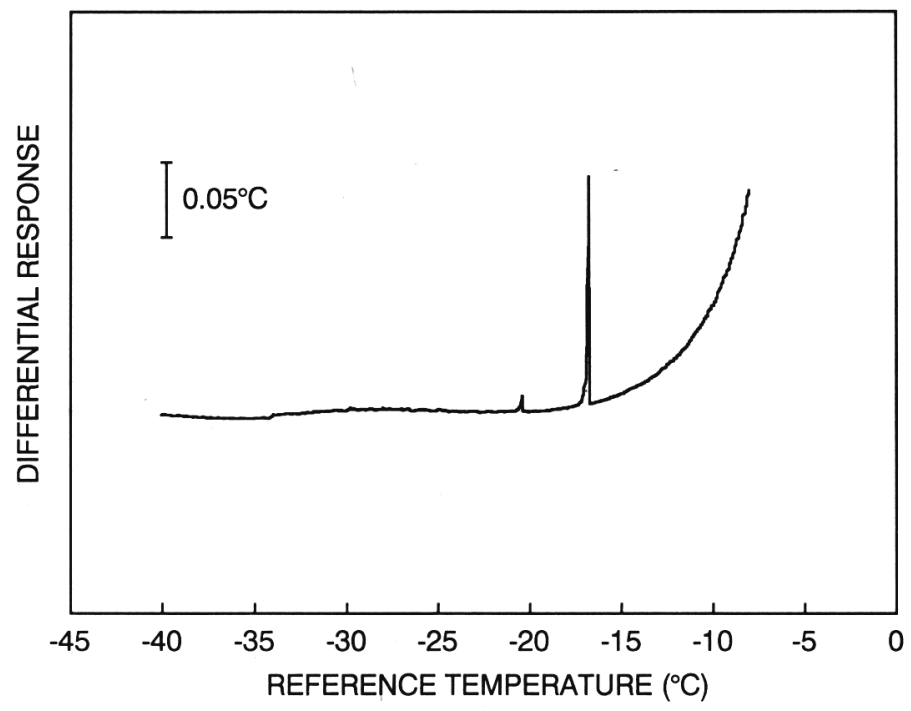

Fig. 2. DTA of a 'Black Satin' blackberry floral bud collected on 5 Feb. 1990. High temperature exotherm not shown.

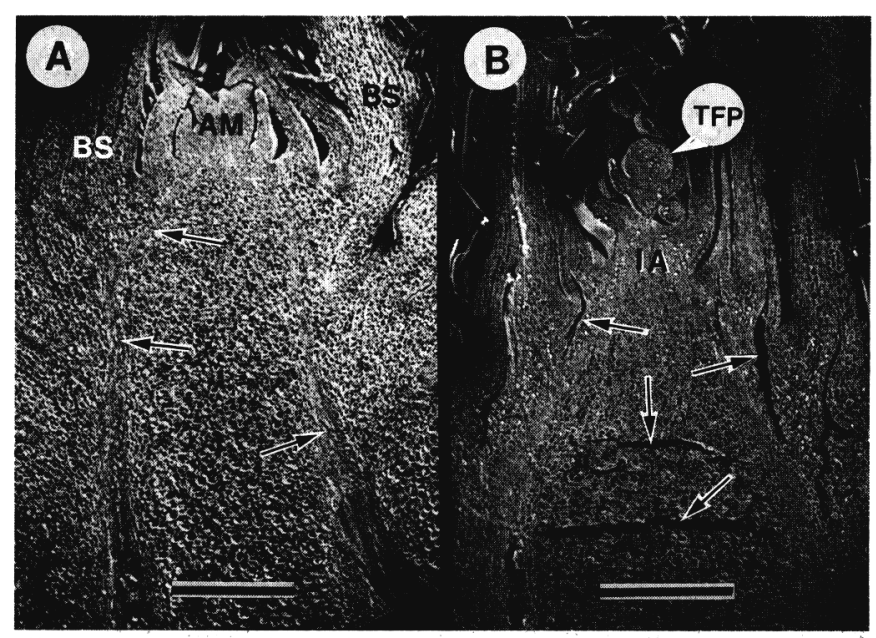

Fig. 3. Scanning electron micrographs of eastern thornless blackberry buds. (A) Nonfrozen bud (stage 1) fixed in FAA at 23C. Note the bud scales (BS) surrounding the undifferentiated apical meristem (AM) and the vascular traces (arrows). (B) Freeze-fixed bud (stage 3) with enlarged inflorescence axis (IA) and terminal floral primordium (TFP). Note that the tissue of the inflorescence axis and the floral primordium is undamaged. Voids are present (arrows) in the bud axis and scales. Bars $=0.5 \mathrm{~mm}$.

buds to supercool and produce LTEs did not correspond to bud development stages or the number of floral primordia per bud. Extracellular ice formed voids in the bud axis and scales of buds -subjected to -5 or $-30 \mathrm{C}$.

\section{Literature Cited}

Andrews, P.K. and E.L. Proebsting, Jr. 1987. Effects of temperature on the deep supercooling characteristics of dormant and deacclimating sweet cherry flower buds. J. Amer. Soc. Hort. Sci. 112:334340 .
Andrews, P.K., C.R. Sandidge, III, and T.K. Toyama. 1984. Deep supercooling of dormant and deacclimating Vitus buds. Amer. J. Enol. Viticult. 35:175-177.

Ashworth, E.N. 1982. Properties of peach flower buds which facilitate supercooling. Plant Physiol. 70:1475-1479.

Ashworth, E.N. 1984. Xylem development in Prunus flower buds and the relationship to deep supercooling. Plant Physiol. 74:862-865.

Ashworth, E.N. 1990. The formation and distribution of ice within forsythia flower buds. Plant Physiol. 92:718-725.

Ashworth, E.N., G.A. Davis, and M.E. Wisniewski. 1989. The formation and distribution of ice within dormant and deacclimated peach flower buds. Plant Cell Environ. 12:521-528.

Biermann, J., C. Stushnoff, and M.J. Burke. 1979. Differential thermal analysis and freezing injury in cold hardy blueberry flower buds. J. Amer. Soc. Hort. Sci. 104:444-449.

Bittenbender, H.C. and G.S. Howell, Jr. 1974. Adaptation of the Spearman-Karber method of estimating $\mathrm{T}_{50}$ of cold stressed flower buds. J. Amer. Soc. Hort. Sci. 99:187-189.

George, M.F. 1982. Freezing avoidance by supercooling of tissue water in vegetative and reproductive structures of Juniperus virginiana, p. 367-377. In P.H. Li and A. Sakai (eds.). Plant cold hardiness and, freezing stress, vol. 2. Academic Press, New York.

Kraut, J., C.S. Walsh, and E.N. Ashworth. 1986. Acclimation and winter hardiness patterns in eastern thornless blackberry. J. Amer. Soc. Hort. Sci. 111:347-352.

MacKenzie, A.P., T.A. Kuster, and B.J. Luyet. 1975. Freeze-fixation at high subzero temperatures. Cryobiology 12:427-439.

Moore, J.N. and J.D. Caldwell. 1985. Rubus, p. 226-238, In: A.H. Halevy (ed.). CRC handbook of flowering. vol. 4. CRC Press, Boca Raton, Fla.

Quamme, H.A. 1974. An exothermic process involved in the freezing injury to flower buds of several Prunus species. J. Amer. Soc. Hort. Sci. 99:315-318.

Robertson, M. 1957. Further investigation of flower-bud development in the genus Rubus. J. Hort. Sci. 32:265-273.

Sass, J.E. 1958. Botanical microtechnique. 3rd (ed.). Iowa State Univ. Press, Ames.

Schaffer, K., M. Warmund, and M. George. 1991a. Anatomical characteristics of selected Rubus and Prunus floral buds which influence their response to freezing temperatures. Plant Physiol. Suppl. 96:58. (Abstr.)

Schaffer, K., M. Warmund, and M. George. 1991b. The role of ice lens formation in determining the number of low temperature exotherms exhibited by 'Darrow' blackberry floral buds: A hypothesis. Plant Physiol. Suppl. 96:58. (Abstr.)

Takeda, F. 1987. Some factors associated with fruit maturity range in cultivars of the. semi-erect, tetraploid thornless blackberry. HortScience 22:405-408.

Takeda, F. and M. Wisniewski. 1989. Organogenesis and patterns of floral bud development in two eastern thornless blackberry cultivars. J. Amer. Soc. Hort. Sci. 114:528-531.

Waldo, G.F. 1933. Fruit bud formation in brambles. Proc. Amer. Soc. Hort. Sci. 30:263-267.

Warmund, M.R. and M.F. George. 1989. Freezing avoidance by supercooling in floral buds and canes of 'Shawnee' blackberry. Acta Hort. 262:333-340.

Warmund, M.R. and M.F. George. 1990. Freezing survival and supercooling in primary and secondary buds of Rubus spp. Can. J. Plant Sci. 70:893-904.

Warmund, M.R., M.F. George, and B.G. Cumbie. 1988. Supercooling in 'Darrow' blackberry buds. J. Amer. Soc. Hort. Sci. 113:418422 